It is in raising these questions in such a precise and concise manner that the great merit of Prof. Weber's book lies, and while we may not agree with him over details, it is undeniable that he has successfully delimited the area where the answers will one day be found.

J. R. BENDALI

\section{METEOROLOGICAL AND IONOSPHERIC STUDIES IN THE ARCTIC}

Polar Atmosphere Symposium, Oslo, 2-8 July, 1956 Part 1: Meteorology Section. Edited by R. C. Sutcliffe. Pp.xi +341. 70s. net. Part 2: Ionospheric Section. Edited by K. Weekes. Pp. xiii +212 . 60s. net. (London and New York: Pergamon Press, 1957 and 1958. AGARDograph No. 29. Published for and on behalf of the Advisory Group for Aeronautical Research and Development, North Atlantic Treaty Organization.)

$\mathrm{D}$

URING and since the Second World War, networks of meteorological observing stations making upper-air observations by radio-sonde have been established in the American Aretic by the United States and Canada, in Greenland by Denmark and the United States and in the Russian sector by the U.S.S.R. In addition, temporary aerological stations have operated on ice floes and observations by regular Arctic weather reconnaissance flights have been made by using 'drop-sondes' along their tracks. It appears, however, that at the time of the conference much of the Arctic aerological data not only remained unpublished but also some were unavailable. The majority of the twenty-four papers on meteorology are concerned with the analysis of the available upper-air data though, besides these synoptic and aerological studies, there are also accounts of the recent climatio changes in the Arctic, of radiation measurements, of visual range and 'whiteout' and of the distribution of ice in Arctic seas. The discussions that followed the papers are admirably reported and make interesting reading, often ranging into wider issues than those raised by the papers that initiated them. They include, for example, an exchange of views between Scherhag, Sutcliffe, Namias and Fjörtoft on the warming effect on the stratosphere which Scherhag some years ago attributed to the occurrence of a solar flare. The revelation that many local winds ascribed to steep slopes are often, in fact, unconnected with the slopes, led to a suggestion that certain classical textbook concepts require revision. A further assertion that the concepts of synoptic analysis should be included in this revision called forth an immediate and vigorous defence of frontal analysis by distin. guished meteorologists.

About half the twenty-one papers presented to the Ionospheric Section deal with the methods, results and theory of ionospheric drift measurements. The discussion naturally centred on the interpretation of the results in different conditions as representing true winds or the effect of electric fields, and on the difficulty of determining the height to which the drift measurements refer. There follow papers on prediction techniques applicable to problems of polar communication, on absorption measurements and one on a theory of meteor echoes of long duration based on atmospheric turbulence. This volume concludes with a short report of a discussion of measurements of absorption associated with the solar event of February 23,1956 .

The planning of work in the Arctic during the International Geophysical Year must have been materially assisted by this meeting of meteorologists and ionospheric physicists at Oslo during the summer of 1956, though it is hinted in at least one of the papers that the concentration of activity on the Antarctic would inevitably limit the scope of the effort in the Arctic.

JAMES PATON

\section{INTRODUCTORY ELECTRONIC THEORY}

\section{An Introduction to Electronic Theories or Organic} Chemistry.

By G. I. Brown. Pp. vii +209 . (London and New York : Longmans, Green and Co., Ltd., 1958.) 15s. net.

A

PROBLEM confronting all writers of elementary text-books on the mechanism of organic reactions is the marriage of theoretical conclusions with suitable experimental evidence which is within the knowledge of the reader. Elementary text-books often have the tendency to particularize general reactions of classes of compounds in terms of the simplest members. These are seldom characteristic members of the class. The problem is a difficult one and the author has courageously, and probably rightly, avoided it by omitting the experimental material so far as possible.

This book is clearly and easily written and the argument simply stated. The usual topics are discussed, including electrophilic and nucleophilic substitution, the molecularity of reaction, hydrolysis, addition and elimination reactions, hydrogen-bonding and homolytic and heterolytic fission. The book has also a good historical introduction and very useful chapters on the nature of bonding. There is also a timely appearance of the high value of the latent heat of sublimation of carbon, evidence for which is now compelling.

As each topic is dealt with separately, the book will prove a ready source of information as well as being useful for reference. The text is clearly printed and attractively presented, the whole work being well indexed. The diagram, except for the point mentioned below, is well constructed and produced.

There are some matters with which I disagree. The discussion of the nitration of $p$-terbutyltoluene comes to an erroneous conclusion; recent evidence strongly favours a steric explanation of the experimental observations. The suggested mechanism for the Hofmann degradation (p. 193), moreover, would not meet with universal approval.

Finally, there are some trivial errors. The display of the electrons in the diagram (p. 34) suggests an interpenetration of the valency orbits of the oxygen atoms, and the failure to assign the $-\mathrm{NO}_{2}$ and - $\mathrm{COOH}$ groups to particular carbon atoms on p. 196 is confusing at first sight. Surprisingly, collinear has been mis-spelt.

In spite of these criticisms, however, I consider the book to be well constructed and deserving of serious study. If it reaches the classes of readers, sixth-form students, first-year university students and older chemists who are interested, as the author wishes, it will do much to ensure a greater appreciation of this important subject.

R. I. REED 